\title{
OPTIMAL INVERSE MODELS FOR BI-MOBILE MECHANISMS OF WALKING ROBOT LEGS
}

\author{
COMANESCU, A.; COMANESCU, D.; \\ DUGAESESCU, I. \& UNGUREANU, L.M.
}

Abstract: The paper brings some theoretical and practical contributions for the optimal design of bi-mobile mechanical systems. The mechanisms with two degrees of mobility are used for mechanical systems such as robot-arms or legs of walking robots, which ensure for the extremity of their effectors any trajectory in a suitable domain. Two theoretical aspects are developed: a structural design method for bimobile planar mechanisms based on their inverse and direct structural modelling and the design of two new passive modular groups with zero degree of mobility obtained from Baranov trusses and applied for the optimal structural design of such mechanisms. The bi-mobile mechanisms firstly presented in the paper are solutions designed by their optimal inverse structural modelling.

Key words: bi-mobile planar mechanism, optimal structure, design method, robot arm, leg
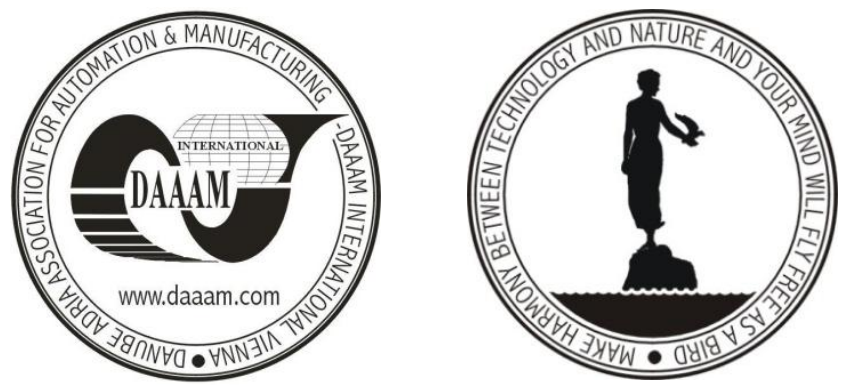

Authors' data: Univ.Prof.Dr.-Ing. Comanescu, A[driana]; Univ.Prelector.Dr.-Ing. Comanescu, D[inu]; Lect.Dr.-Ing. Dugaesescu, I[leana]; Phd.Student-Ing. Ungureanu, L[iviu] M[arian], Mechanisms and Robots Theory Department within the Faculty of Engineering and Technological Systems Management, University Politehnica of Bucharest, Splaiul Independentei 313, 060042, Bucharest, Romania, adrianacomanescu@gmail.com,dinucomanescu@yahoo.com, ileana_d1@yahoo.com, ungureanu.liviu.marian@gmail.com

This Publication has to be referred as: Comanescu, A[driana]; Comanescu, D[inu]; Dugaesescu, I[leana] \& Ungureanu, L[iviu] M[arian] (2013) Optimal Inverse Models for Bi-Mobile Mechanisms of Walking Robot Legs, Chapter 21 in DAAAM International Scientific Book 2013, pp. 417-430, B. Katalinic \& Z. Tekic (Eds.), Published by DAAAM International, ISBN 978-3-901509-94-0, ISSN 1726-9687, Vienna, Austria

DOI: 10.2507/daaam.scibook.2013.21 
Comanescu, A.; Comanescu, D.; Dugaesescu, I. \& Ungureanu, L.M.: Optimal Inver...

\section{Introduction}

The structural design of bi-mobile planar mechanisms is based on the solutions of linkages with 5 degrees of freedom, respectively two degrees of mobility and a given number of the independent loops (contours). In the literature (Crossley, 1968; Manolescu et al., 1972; Pelecudi, 1967) one may find a single linkage with an independent contour, four bi-loops linkages and 40 linkages with three independent loops (Fig. 1). The effector extremity of such mechanism may describe any curve in the evolution domain of the mechanism.

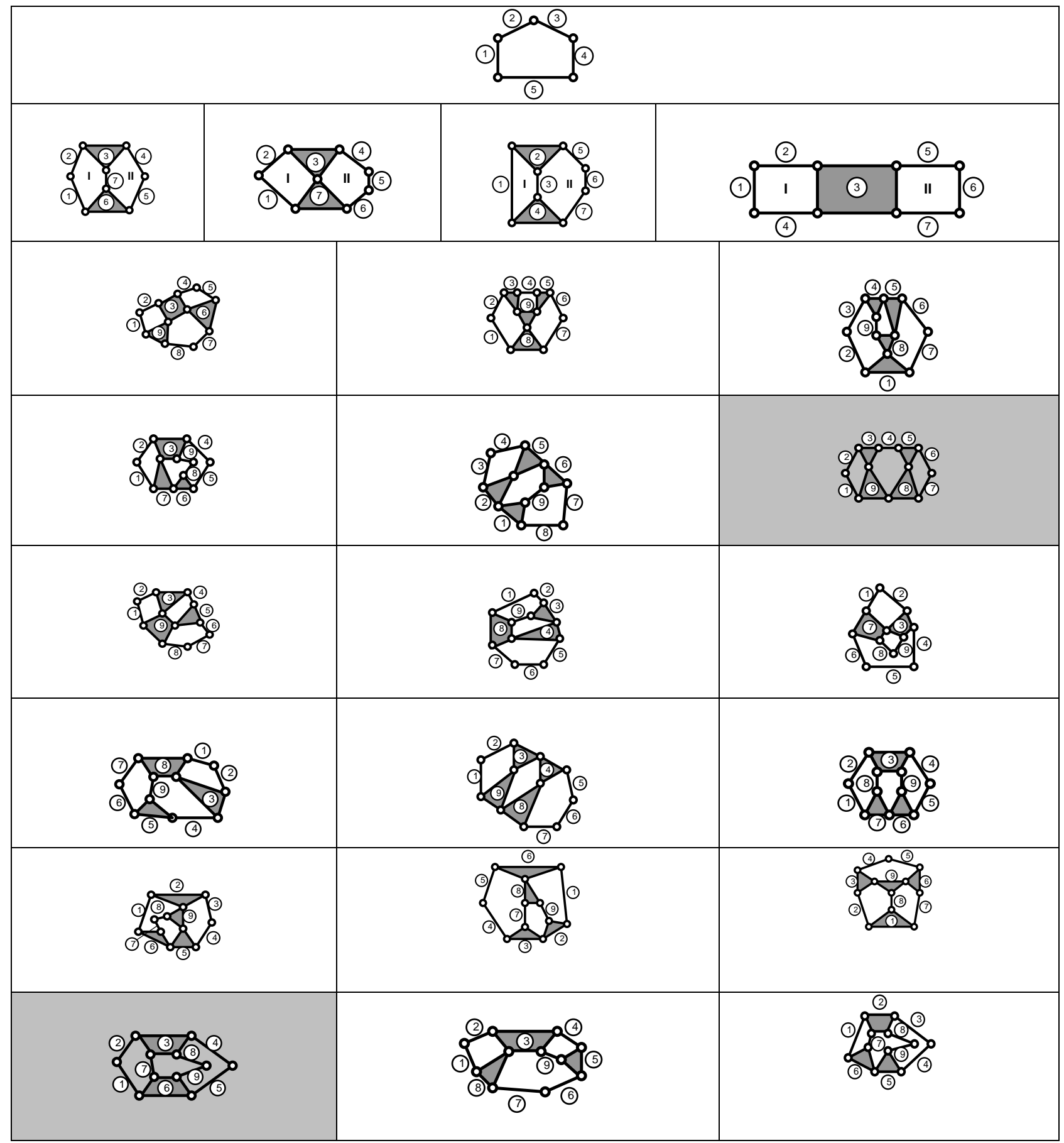




\begin{tabular}{|c|c|c|}
\hline & \\
\hline & & \\
\hline
\end{tabular}

Fig. 1. The planar linkages with five degrees of freedom

A bi-mobile planar mechanism with an optimal structure used either for a robot arm or for a leg of a walking robot must contain a minimum number of modular passive groups (Fig. 2) for the inverse model and also a minimum number of modular groups for the direct model (Crossley, 1968; Manolescu et al., 1972; Pelecudi, 1967). 
Comanescu, A.; Comanescu, D.; Dugaesescu, I. \& Ungureanu, L.M.: Optimal Inver...

Baranov Truss(BT)

Fig. 2. The passive modular groups

In order to design structures for bi-mobile mechanisms the following steps are mentioned (Crossley, 1968; Comanescu et al., 2010):

- to put into evidence the matrix of possible bases and effectors for the linkages adopted from Fig. 1;

- to eliminate the non-distinct solutions due to the symmetrical characteristics of the linkages; 
- to verify the solutions for bases and effectors through the inverse structural model characterized by a zero instantaneous degree of mobility;

- the selection of the optimum structural-constructive solutions including a minimum number of passive modular groups;

- to place in the mechanism structure the active kinematic pairs (actuators);

- to create an optimal structural solution with a minimum number of modular groups.

The mobility instantaneously becomes zero due to the placing a connection between the basis and the extremity of the effectors and the inverse model has zero degree of mobility. This connection is equivalent to a lower pair with two constrains and a single mobility.

\section{Inverse Structural Model Characteristics}

Any structure with zero degree of mobility has an odd number of links. The planar structures with zero degree of mobility are distinct, named Baranov trusses in the literature (Crossley, 1968; Manolescu et al., 1972; Comanescu et al., 2010) and known in number of 33 solutions (Fig. 3). From these structures the passive modular groups already known are obtained by eliminating a link and the pairs are placed to its adjacent links. Consequently such modular group is an open, non-composed linkage with an even number of links (Fig. 2).

(2) (3)

Fig. 3. The Baranov trusses 
Comanescu, A.; Comanescu, D.; Dugaesescu, I. \& Ungureanu, L.M.: Optimal Inver...

Having in view the inverse model of a bi-mobile mechanism previously mentioned it is possible to note its odd number of links. By excluding its basis the structure is composed by an even number of links, which determine passive modular groups (Fig. 2).

In the case of the planar bi-mobile linkages (Fig. 1) the inverse model has 8 links. The passive modular groups presented in Fig. 2 have 2, 4, 6 links. Other new passive modular groups, never found in the literature may be obtained from Baranov trusses with 9 links.

The paper puts into evidence such new passive modular groups.

The major function of an inverse model is that to determine the parameters of the active pairs (actuators) relative to the characteristics of the extremity of the effector. In the teaching process the mechanism is more precise if it has a minimum number of passive modular groups.

A bi-mobile linkage with 9 links and three loops (Fig. 3) may have an inverse model constituted by the following passive modular groups formed by: $2+2+2+2$, $2+4+2,2+2+4,4+2+2,2+6,6+2$ or 8 elements. Some groups with 8 links are deduced from a Baranov trusses and presented in the next paragraphs.

\section{Basis-effector Matrix for Bi-mobile Linkages and Distinct Solutions}

The basis and the effector must satisfy the following theorems:

- the effector must have a planar motion depending on two independent parameters;

- the effector can not be adjacent to the basis;

- the basis and the effector can not belong to the same four bars linkage (Fig. 4. a), Watt linkage (Fig. 4. b) or Stephenson linkage (Fig. 4. c).
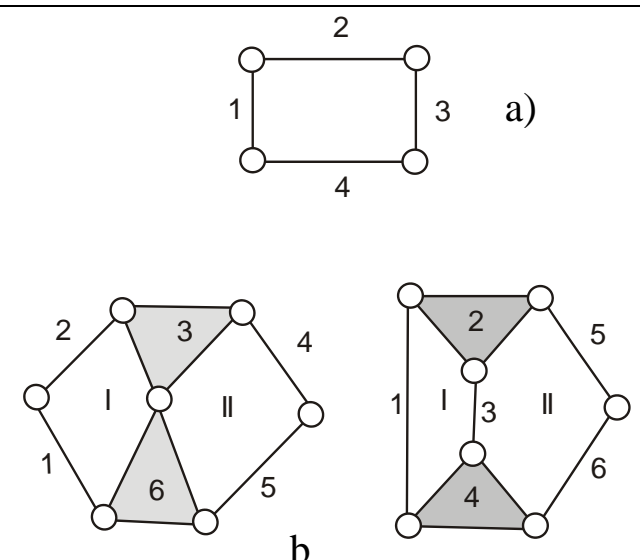

c)

Fig. 4. a) Four bars linkage, b) Watt linkage, c) Stephenson linkage

There are selected some linkages from Fig.1 for which the basis-effector matrices are given. Such matrix is square, symmetric and the null elements of the principal diagonal, because the basis can not be an effector in the same time. It has the form presented in (1). 


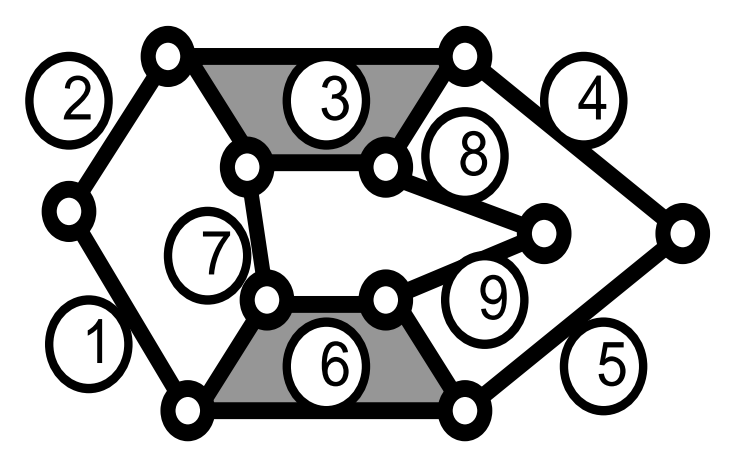

Fig. 5. Three loops planar linkage

$$
\mathrm{A}=\left[\begin{array}{lllllllll}
0 & 0 & 1 & 1 & 1 & 0 & 1 & 1 & 1 \\
0 & 0 & 0 & 1 & 1 & 1 & 1 & 1 & 1 \\
1 & 0 & 0 & 0 & 1 & 1 & 0 & 0 & 1 \\
1 & 1 & 0 & 0 & 0 & 1 & 1 & 1 & 1 \\
1 & 1 & 1 & 0 & 0 & 0 & 1 & 1 & 1 \\
0 & 1 & 1 & 1 & 0 & 0 & 0 & 1 & 0 \\
1 & 1 & 0 & 1 & 1 & 0 & 0 & 1 & 1 \\
1 & 1 & 0 & 1 & 1 & 1 & 1 & 0 & 0 \\
1 & 1 & 1 & 1 & 1 & 0 & 1 & 0 & 0
\end{array}\right]
$$

The linkage has the following symmetrical links: $1=2,3=6,8=4=5=9$. There are 15 distinct solutions as follows:

\begin{tabular}{|c|c|c|c|}
\hline $\mathrm{A}(1,3) \equiv \mathrm{A}(2,6)$ & $\mathrm{A}(3,1) \equiv \mathrm{A}(6,2)$ & $\begin{array}{c}\mathrm{A}(3,5) \equiv \mathrm{A}(6,4) \equiv \\
\mathrm{A}(3,9) \equiv \mathrm{A}(6,8)\end{array}$ & $\begin{array}{c}\mathrm{A}(5,3) \equiv \mathrm{A}(4,6) \equiv \\
\mathrm{A}(9,3) \equiv \mathrm{A}(8,6)\end{array}$ \\
\hline $\begin{array}{c}\mathrm{A}(1,4) \equiv \mathrm{A}(1,8) \equiv \\
\mathrm{A}(2,5) \equiv \mathrm{A}(2,9)\end{array}$ & $\begin{array}{c}\mathrm{A}(4,1) \equiv \mathrm{A}(8,1) \equiv \\
\mathrm{A}(5,2) \equiv \mathrm{A}(9,2)\end{array}$ & $\mathrm{A}(3,6) \equiv \mathrm{A}(6,3)$ & \\
\hline $\begin{array}{c}\mathrm{A}(1,5) \equiv \mathrm{A}(1,9) \equiv \\
\mathrm{A}(2,4) \equiv \mathrm{A}(2.8)\end{array}$ & $\begin{array}{c}\mathrm{A}(5,1) \equiv \mathrm{A}(9,1) \equiv \\
\mathrm{A}(4,2) \equiv \mathrm{A}(8,2)\end{array}$ & $\begin{array}{c}\mathrm{A}(4,7) \equiv \mathrm{A}(8,7) \equiv \\
\mathrm{A}(5,7) \equiv \mathrm{A}(9,7)\end{array}$ & $\begin{array}{c}\mathrm{A}(7,4) \equiv \mathrm{A}(7,8) \equiv \\
\mathrm{A}(7,5) \equiv \mathrm{A}(7,9)\end{array}$ \\
\hline $\mathrm{A}(1,7) \equiv \mathrm{A}(2,7)$ & $\mathrm{A}(7,1) \equiv \mathrm{A}(7,2)$ & $\begin{array}{c}\mathrm{A}(4,8) \equiv \mathrm{A}(8,4) \equiv \\
\mathrm{A}(5,9) \equiv \mathrm{A}(9,5)\end{array}$ & \\
\hline & & $\begin{array}{c}\mathrm{A}(4,9) \equiv \mathrm{A}(9,4) \equiv \\
\mathrm{A}(5,8) \equiv \mathrm{A}(8,5)\end{array}$ & \\
\hline
\end{tabular}

Tab.1. Solutions for symmetrical links: $1=2,3=6,8=4=5=9$

The inverse models for these solutions and their passive modular groups connections are the following: 
Comanescu, A.; Comanescu, D.; Dugaesescu, I. \& Ungureanu, L.M.: Optimal Inver...
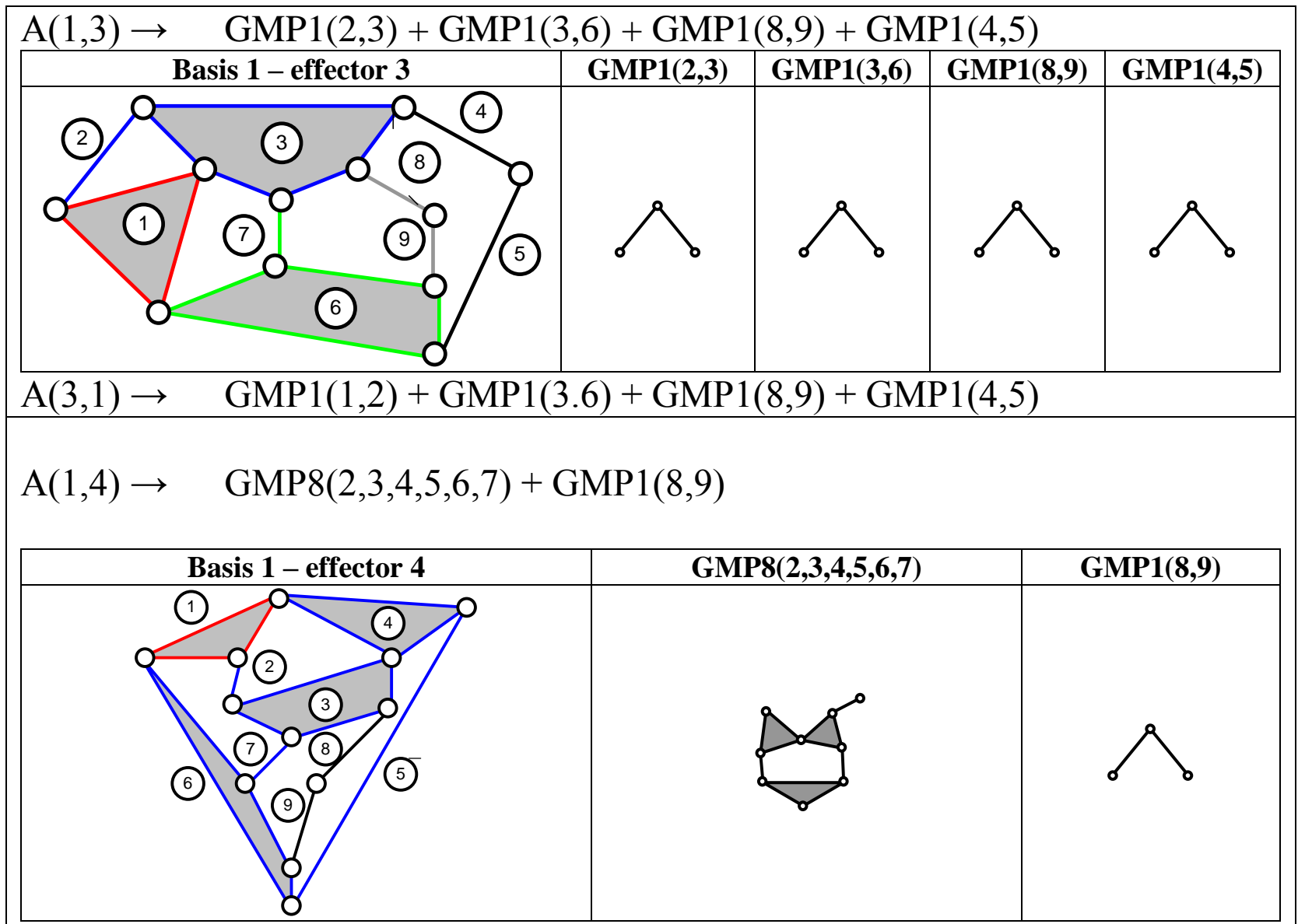

$\mathrm{A}(4,1) \rightarrow \quad \operatorname{GMP} 8(1,2,3,5,6,7)+\operatorname{GMP} 1(8,9)$

$\mathrm{A}(1,5) \rightarrow \quad \operatorname{GMP} 1(5,6)+\operatorname{GMP} 2(2,3,4,7)+\operatorname{GMP} 1(8,9)$
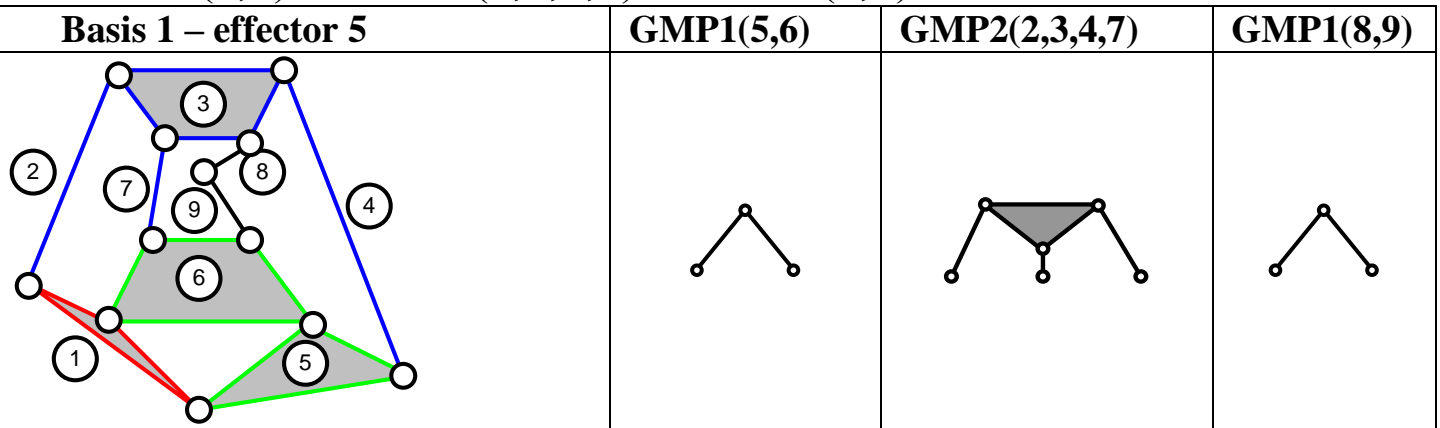

$\mathrm{A}(5,1) \rightarrow \operatorname{GMP} 1(1,6)+\operatorname{GMP} 2(2,3,4,7)+\operatorname{GMP} 1(8,9)$

$\mathrm{A}(1,7) \rightarrow \operatorname{GMP} 1(6,7)+\operatorname{GMP} 1(2,3)+\operatorname{GMP} 1(8,9)+\operatorname{GMP} 1(4,5)$

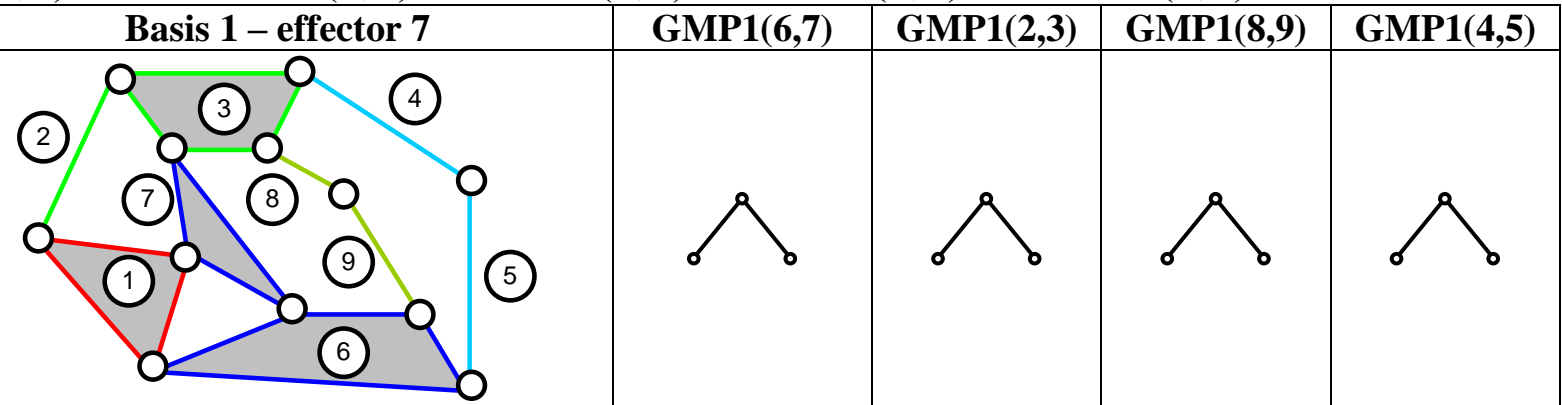

$\mathrm{A}(7,1) \rightarrow \quad \operatorname{GMP} 1(6,7)+\operatorname{GMP} 1(2,3)+\operatorname{GMP} 1(8,9)+\operatorname{GMP} 1(4,5)$

$\mathrm{A}(3,5) \rightarrow \quad \operatorname{GMP} 1(4,5)+\operatorname{GMP} 1(6,7)+\operatorname{GMP} 1(8,9)+\operatorname{GMP} 1(1,2)$ 


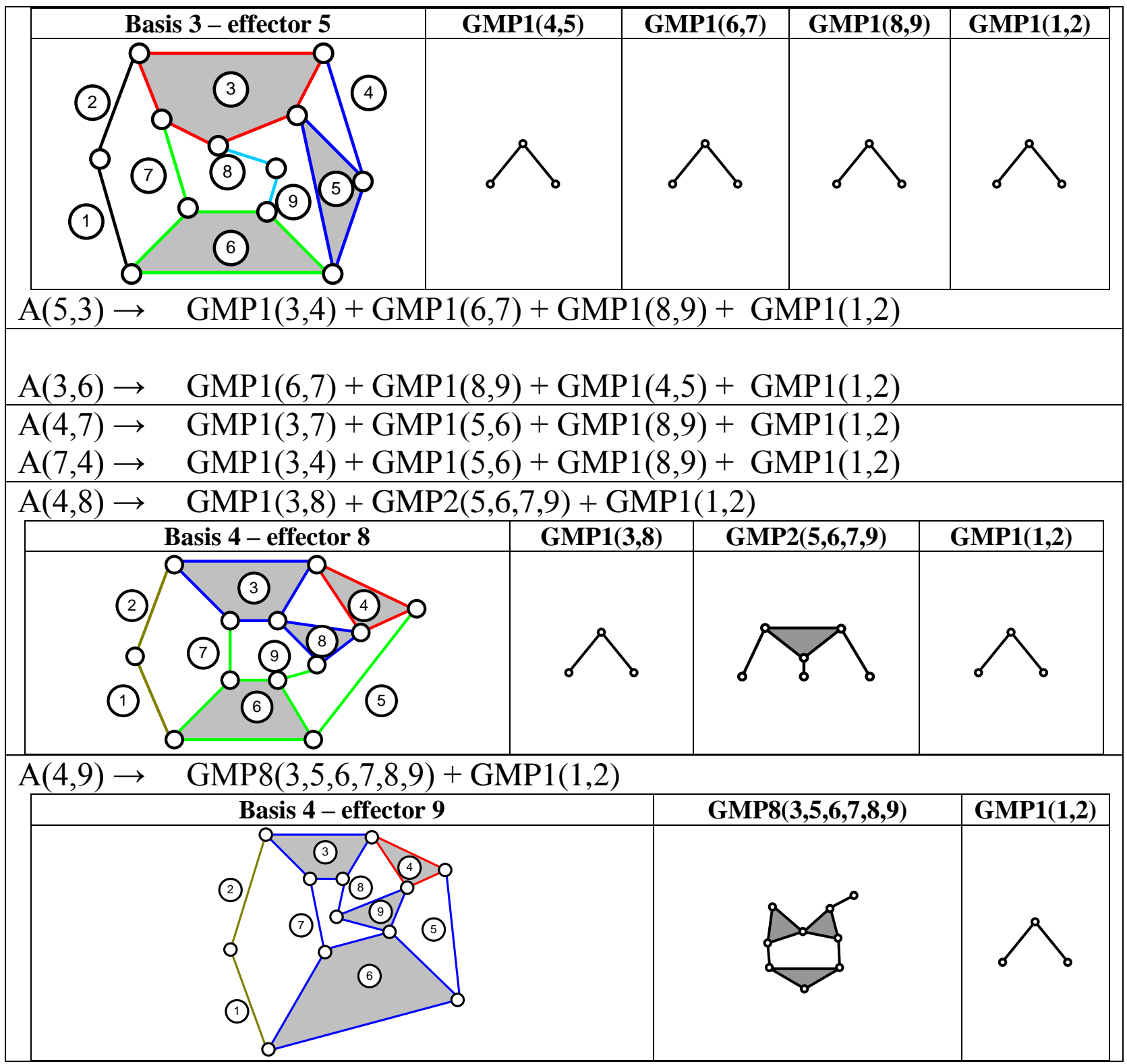

Tab.2. The inverse models for the solutions and the passive modular groups connections

The basis-effector matrix (2) for the linkage given in Fig. 6 is also presented.

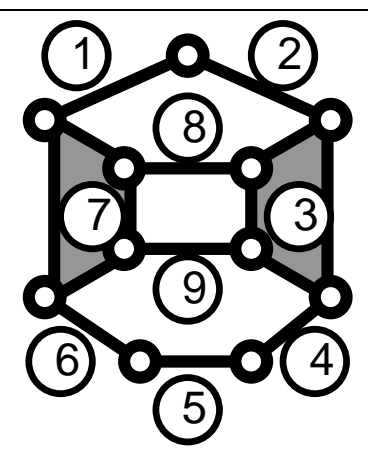

Fig. 6. Three loops planar linkage 
Comanescu, A.; Comanescu, D.; Dugaesescu, I. \& Ungureanu, L.M.: Optimal Inver...

$$
A=\left[\begin{array}{lllllllll}
0 & 0 & 0 & 1 & 1 & 1 & 0 & 0 & 0 \\
0 & 0 & 0 & 1 & 1 & 1 & 0 & 0 & 0 \\
0 & 0 & 0 & 0 & 1 & 1 & 0 & 0 & 0 \\
1 & 1 & 0 & 0 & 0 & 1 & 1 & 1 & 1 \\
1 & 1 & 1 & 0 & 0 & 0 & 1 & 1 & 1 \\
1 & 1 & 1 & 1 & 0 & 0 & 0 & 1 & 1 \\
0 & 0 & 0 & 1 & 1 & 0 & 0 & 0 & 0 \\
0 & 0 & 0 & 1 & 1 & 1 & 0 & 0 & 0 \\
0 & 0 & 0 & 1 & 1 & 1 & 0 & 0 & 0
\end{array}\right]
$$

The links $1=2,4=6,3=7,8=9$ are symmetrical ones, so that it is possible to obtain 15 distinct solutions as follows:

\begin{tabular}{|l|l|l|l|}
\hline $\mathrm{A}(1,4) \equiv \mathrm{A}(2,6)$ & $\mathrm{A}(4,1) \equiv \mathrm{A}(6,2)$ & $\mathrm{A}(3,5) \equiv \mathrm{A}(7,5)$ & $\mathrm{A}(5,3) \equiv \mathrm{A}(5,7)$ \\
\hline $\mathrm{A}(1,5) \equiv \mathrm{A}(2,5)$ & $\mathrm{A}(5,1) \equiv \mathrm{A}(5,2)$ & $\mathrm{A}(3,6) \equiv \mathrm{A}(7,4)$ & $\mathrm{A}(6,3) \equiv \mathrm{A}(4,7)$ \\
\hline $\mathrm{A}(1,6) \equiv \mathrm{A}(2,4)$ & $\mathrm{A}(6,1) \equiv \mathrm{A}(4,2)$ & $\mathrm{A}(4,6)$ & \\
\hline & & $\mathrm{A}(4,8) \equiv \mathrm{A}(4,9) \equiv$ & $\mathrm{A}(8,4) \equiv \mathrm{A}(9,4) \equiv$ \\
& & $\mathrm{A}(6,8) \equiv \mathrm{A}(6,9)$ & $\mathrm{A}(8,6) \equiv \mathrm{A}(9,6)$ \\
\hline & & $\mathrm{A}(5,8) \equiv \mathrm{A}(5,9)$ & $\mathrm{A}(8,5) \equiv \mathrm{A}(9,5)$ \\
\hline
\end{tabular}

Tab.3. Solutions for symmetrical links: $1=2,4=6,3=7,8=9$

The passive modular groups connections for these solutions are:

\begin{tabular}{|l}
$\mathrm{A}(1,4) \rightarrow \quad$ GMP4 $(2,3,4,7,8,9)+\operatorname{GMP} 1(5,6)$ \\
$\mathrm{A}(4,1) \rightarrow \quad$ GMP13 $(1,2,3,7,8,9)+\mathrm{GMP} 1(5,6)$ \\
$\mathrm{A}(1,5) \rightarrow \quad$ BT $30-$ Baranov truss
\end{tabular}
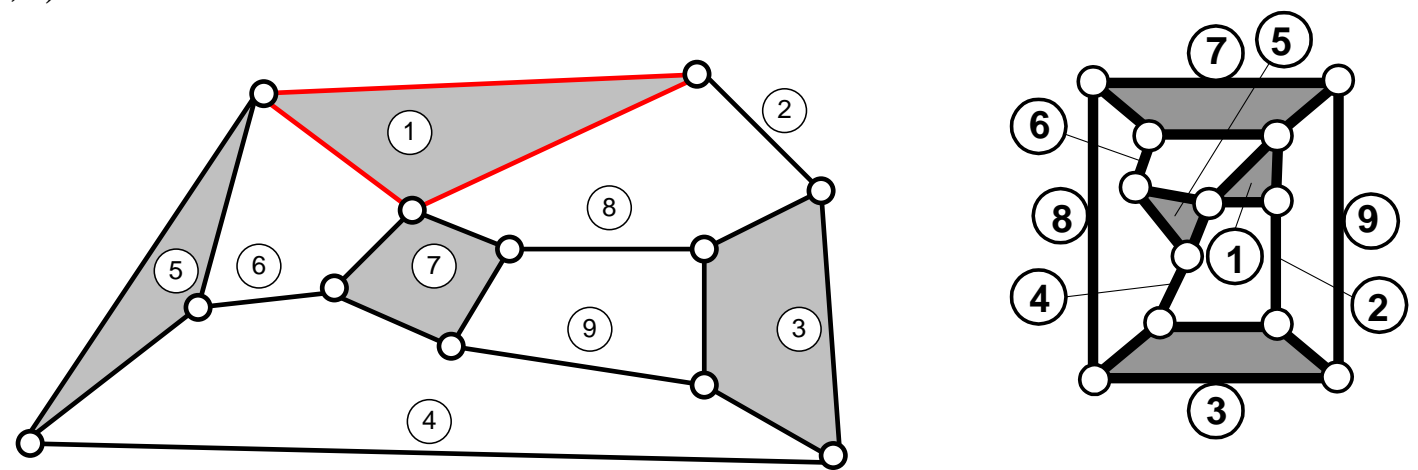

$\mathrm{A}(5,1) \rightarrow$ BT $30-$ Baranov truss

$\mathrm{A}(1,6) \rightarrow \operatorname{GBP} 1(6,7)+\mathrm{GMP} 2(2,3,8,9)+\mathrm{GMP} 1(4,5)$
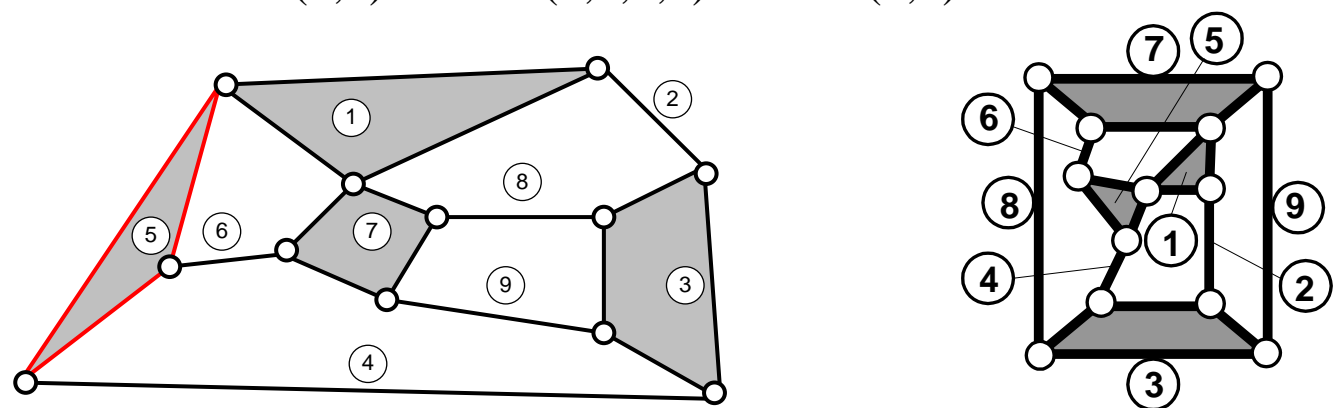

$\mathrm{A}(6,1) \rightarrow \operatorname{GBP} 1(1,7)+\mathrm{GMP} 2(2,3,8,9)+\mathrm{GMP} 1(4,5)$ 


\begin{tabular}{|c|c|c|}
\hline $\mathrm{A}(3,5)$ & $\rightarrow$ & GBP1 $(4,5)+\operatorname{GMP} 2(6,7,8,9)+\operatorname{GMP} 1(1,2)$ \\
\hline $\mathrm{A}(5,3)$ & $\rightarrow$ & $\operatorname{GBP} 1(3,4)+\operatorname{GMP} 2(6,7,8,9)+\operatorname{GMP} 1(1,2)$ \\
\hline $\mathrm{A}(3,6)$ & $\rightarrow$ & GMP2 $(6,7,8,9)+\operatorname{GMP} 1(4,5)+\operatorname{GMP} 1(1,2)$ \\
\hline $\mathrm{A}(6,3)$ & $\rightarrow$ & GMP2(3,7,8,9)+GMP1 $(4,5)+\operatorname{GMP} 1(1,2)$ \\
\hline $\mathrm{A}(4,6)$ & $\rightarrow$ & $\operatorname{GMP} 1(5,6)+\operatorname{GMP} 3(3,7,8,9)+\operatorname{GMP} 1(1,2)$ \\
\hline $\mathrm{A}(4,8)$ & $\rightarrow$ & $\operatorname{GMP} 1(3,8)+\operatorname{GMP} 1(7,9)+\operatorname{GMP} 1(5,6)+\operatorname{GMP} 1(1,2)$ \\
\hline $\mathrm{A}(8,4)$ & $\rightarrow$ & $\operatorname{GMP} 1(3,4)+\operatorname{GMP} 1(7,9)+\operatorname{GMP} 1(5,6)+\operatorname{GMP} 1(1,2)$ \\
\hline $\mathrm{A}(5,8)$ & $\rightarrow$ & GMP5 $(3,4,6,7,8,9)+\operatorname{GMP} 1(1,2)$ \\
\hline $\mathrm{A}(8,5)$ & $\rightarrow$ & $\operatorname{GMP} 9(3,4,5,6,7,9)+\operatorname{GMP} 1(1,2)$ \\
\hline
\end{tabular}

Tab.4.The passive modular groups connections

In a similar way the linkage from Fig. 7 is analyzed. The basis-effector matrix is also given and due to its symmetrical links $1=7,2=6,8=9,3=5$ the following 21 distinct solutions are mentioned:

\begin{tabular}{|c|c|c|c|}
\hline $\mathrm{A}(1,4) \equiv \mathrm{A}(7,4)$ & $\mathrm{A}(4,1) \equiv \mathrm{A}(4,7)$ & $\mathrm{A}(2,4) \equiv \mathrm{A}(6,4)$ & $\mathrm{A}(4,2) \equiv \mathrm{A}(4,6)$ \\
\hline $\mathrm{A}(1,5) \equiv \mathrm{A}(7,3)$ & $\mathrm{A}(5,1) \equiv \mathrm{A}(3,7)$ & $\mathrm{A}(2,5) \equiv \mathrm{A}(6,3)$ & $\mathrm{A}(5,2) \equiv \mathrm{A}(3,6)$ \\
\hline $\mathrm{A}(1,6) \equiv \mathrm{A}(7,2)$ & $\mathrm{A}(6,1) \equiv \mathrm{A}(2,7)$ & $\mathrm{A}(2,6) \equiv \mathrm{A}(6,2)$ & \\
\hline $\mathrm{A}(1,7) \equiv \mathrm{A}(7,1)$ & & $\mathrm{A}(2,8) \equiv \mathrm{A}(6,9)$ & $\mathrm{A}(8,2) \equiv \mathrm{A}(9,6)$ \\
\hline $\mathrm{A}(1,8) \equiv \mathrm{A}(7,9)$ & $\mathrm{A}(8,1) \equiv \mathrm{A}(9,7)$ & $\mathrm{A}(3,5) \equiv \mathrm{A}(5,3)$ & \\
\hline & & $\mathrm{A}(3,8) \equiv \mathrm{A}(5,9)$ & $\mathrm{A}(8,3) \equiv \mathrm{A}(9,5)$ \\
\hline & & $\mathrm{A}(4,8) \equiv \mathrm{A}(4,9)$ & $\mathrm{A}(8,4) \equiv \mathrm{A}(9,4)$ \\
\hline
\end{tabular}

Tab.5. Solutions for symmetrical links: $1=7,2=6,8=9,3=5$.

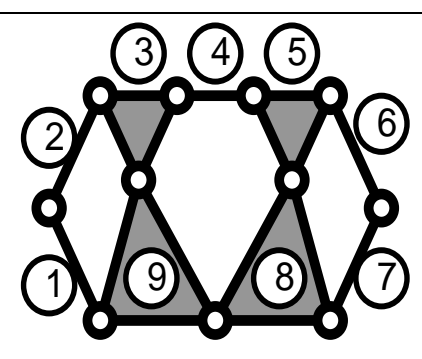

Fig. 7. Three loops planar linkage

$$
A=\left[\begin{array}{lllllllll}
0 & 0 & 0 & 1 & 1 & 1 & 1 & 1 & 0 \\
0 & 0 & 0 & 1 & 1 & 1 & 1 & 1 & 0 \\
0 & 0 & 0 & 0 & 1 & 1 & 1 & 1 & 0 \\
1 & 1 & 0 & 0 & 0 & 1 & 1 & 1 & 1 \\
1 & 1 & 1 & 0 & 0 & 0 & 0 & 0 & 1 \\
1 & 1 & 1 & 1 & 0 & 0 & 0 & 0 & 1 \\
1 & 1 & 1 & 1 & 0 & 0 & 0 & 0 & 1 \\
1 & 1 & 1 & 1 & 0 & 0 & 0 & 0 & 0 \\
0 & 0 & 0 & 1 & 1 & 1 & 1 & 0 & 0
\end{array}\right]
$$

The passive modular groups connections for all inverse models are also presented: 
Comanescu, A.; Comanescu, D.; Dugaesescu, I. \& Ungureanu, L.M.: Optimal Inver...

\begin{tabular}{|l}
$\mathrm{A}(1,4) \rightarrow \mathrm{GMP} 2(2,3,4,9)+\mathrm{GMP} 1(5,8)+\mathrm{GMP} 1(6,7)$ \\
$\mathrm{A}(4,1) \rightarrow \mathrm{GMP} 3(1,2,3,9)+\mathrm{GMP} 1(5,8)+\mathrm{GMP} 1(6,7)$ \\
$\mathrm{A}(1,5) \rightarrow \mathrm{GMP} 8(2,3,4,5,8,9)+\operatorname{GMP} 1(6,7)$ \\
$\mathrm{A}(5,1) \rightarrow \mathrm{GMP} 8(1,2,3,4,8,9)+\operatorname{GMP} 1(6,7)$ \\
$\mathrm{A}(1,6) \rightarrow$ Baranov truss BT 9
\end{tabular}

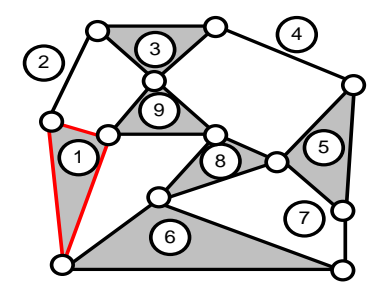

$\mathrm{A}(6,1) \rightarrow$ Baranov truss BT 9

$\mathrm{A}(1,7) \rightarrow$ Baranov truss BT 9

$\mathrm{A}(7,1) \rightarrow$ Baranov truss BT 9

$\mathrm{A}(1,8) \rightarrow \operatorname{GMP} 1(8,9)+\operatorname{GMP} 1(2,3)+\operatorname{GMP} 1(4,5)+\operatorname{GMP} 1(6,7)$

$\mathrm{A}(8,1) \rightarrow \mathrm{GMP} 1(1,9)+\mathrm{GMP} 1(2,3)+\mathrm{GMP} 1(4,5)+\mathrm{GMP} 1(6,7)$

$\mathrm{A}(2,4) \rightarrow \operatorname{GMP} 1(3,4)+\operatorname{GMP} 1(1,9)+\operatorname{GMP} 1(5,8)+\operatorname{GMP} 1(6,7)$

$\mathrm{A}(4,2) \rightarrow \mathrm{GMP} 1(2,3)+\mathrm{GMP} 1(1,9)+\operatorname{GMP} 1(5,8)+\mathrm{GMP} 1(6,7)$

$\mathrm{A}(2,5) \rightarrow \operatorname{GMP} 8(1,3,4,5,8,9)+\operatorname{GMP} 1(6,7)$
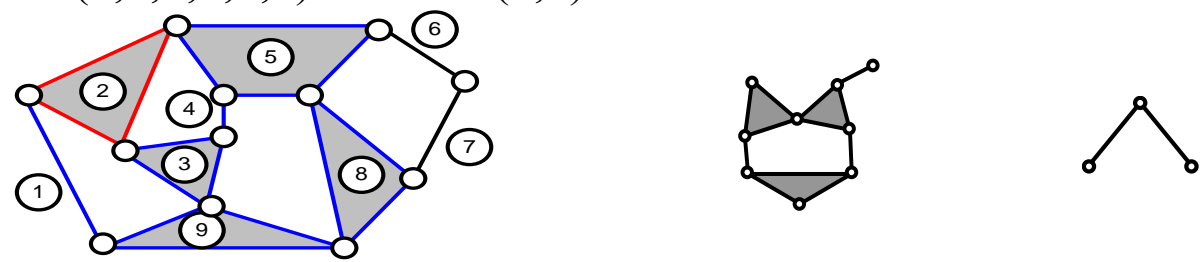

$\mathrm{A}(5,2) \rightarrow \quad \operatorname{GMP} 6(1,2,3,4,8,9)+\operatorname{GMP} 1(6,7)$

$\mathrm{A}(2,6) \rightarrow \quad$ Baranov truss BT 6
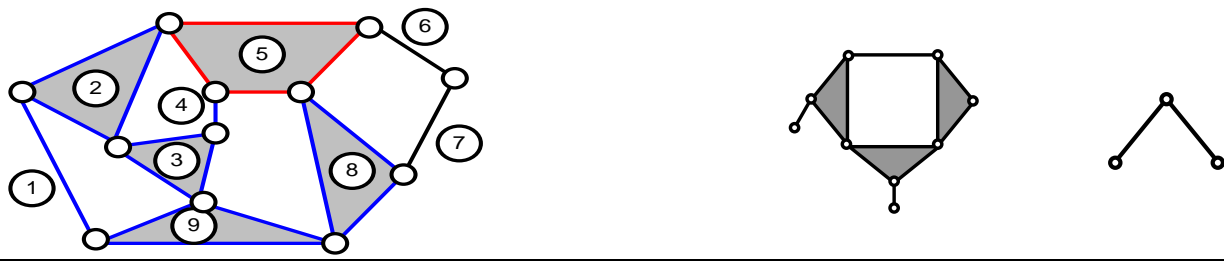

$\mathrm{A}(2,8) \rightarrow$
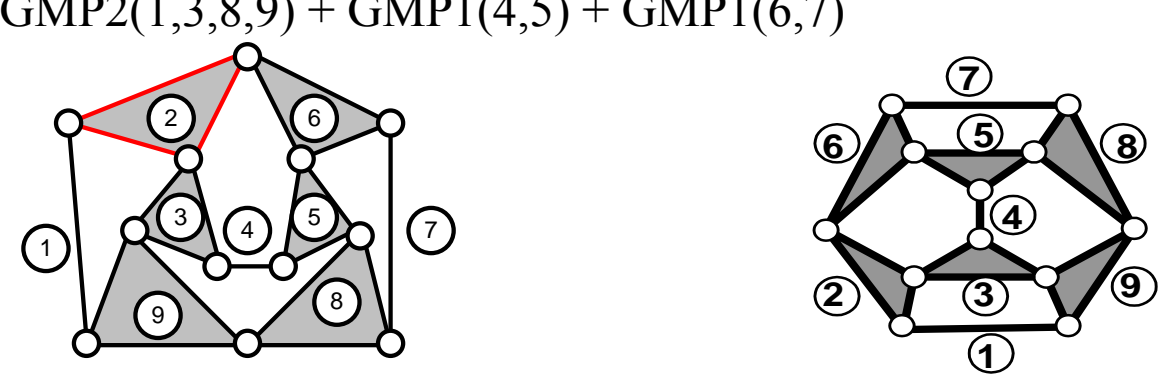

$\mathrm{A}(8,2) \rightarrow \quad \operatorname{GMP} 3(1,2,3,9)+\operatorname{GMP} 1(4,5)+\operatorname{GMP} 1(6,7)$

$\mathrm{A}(3,5) \rightarrow \quad \operatorname{GMP} 1(4,5)+\operatorname{GMP} 1(8,9)+\operatorname{GMP} 1(1,2)+\operatorname{GMP} 1(6,7)$

$\mathrm{A}(3,8) \rightarrow \quad \operatorname{GMP} 1(8,9)+\mathrm{GMP} 1(4,5)+\operatorname{GMP} 1(6,7)+\mathrm{GMP} 1(1,2)$

$\mathrm{A}(8,3) \rightarrow \quad \operatorname{GMP} 1(3,9)+\operatorname{GMP} 1(4,5)+\operatorname{GMP} 1(6,7)+\operatorname{GMP} 1(1,2)$

$\mathrm{A}(4,8) \rightarrow \quad \operatorname{GMP} 1(5,8)+\operatorname{GMP} 1(6,7)+\operatorname{GMP} 1(3,9)+\operatorname{GMP} 1(1,2)$

$\mathrm{A}(8,4) \rightarrow \quad \operatorname{GMP} 1(4,5)+\operatorname{GMP} 1(6,7)+\operatorname{GMP} 1(3,9)+\operatorname{GMP} 1(1,2)$

Tab.6. The passive modular groups connections for all inverse models. 


\section{New Solutions for Bi-Mobile Mechanisms of Walking Robot Legs}

The inverse models previously mentioned are used to design new solutions for bi-mobile mechanisms.

By adopting the linkage from Fig. 5 with the 1 link for frame and the 3 link for effector a constructive solution is presented in Fig. 8. The modular connection $2+2+2+2$ is less indicated due to its inferior precision.

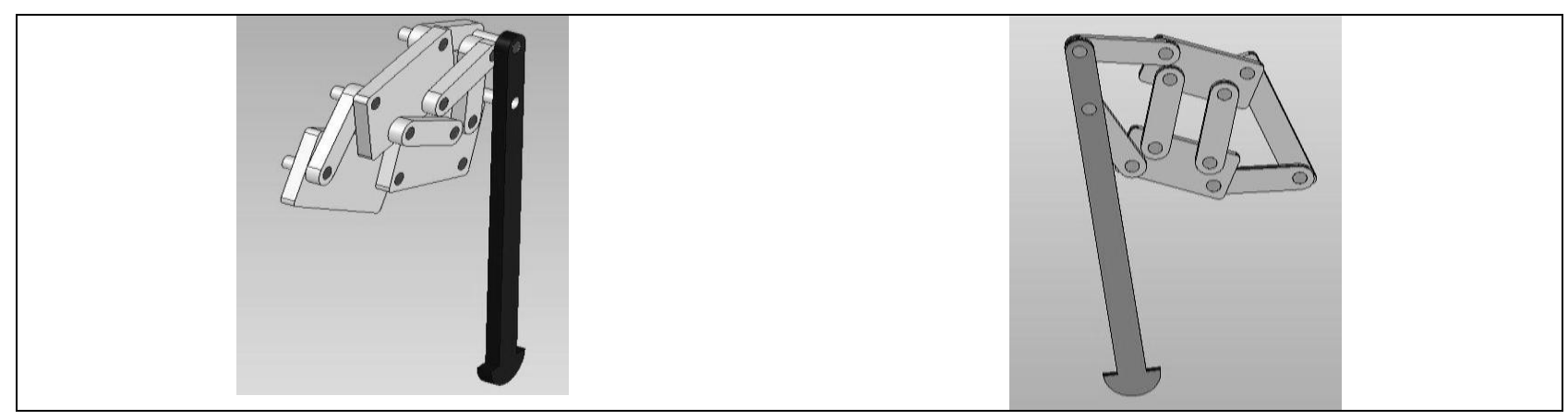

Fig. 8. Constructive solution with 1 link Fig. 9. Optimal solution using 1 link for for frame and the 3 effector link frame and the 5 effector link

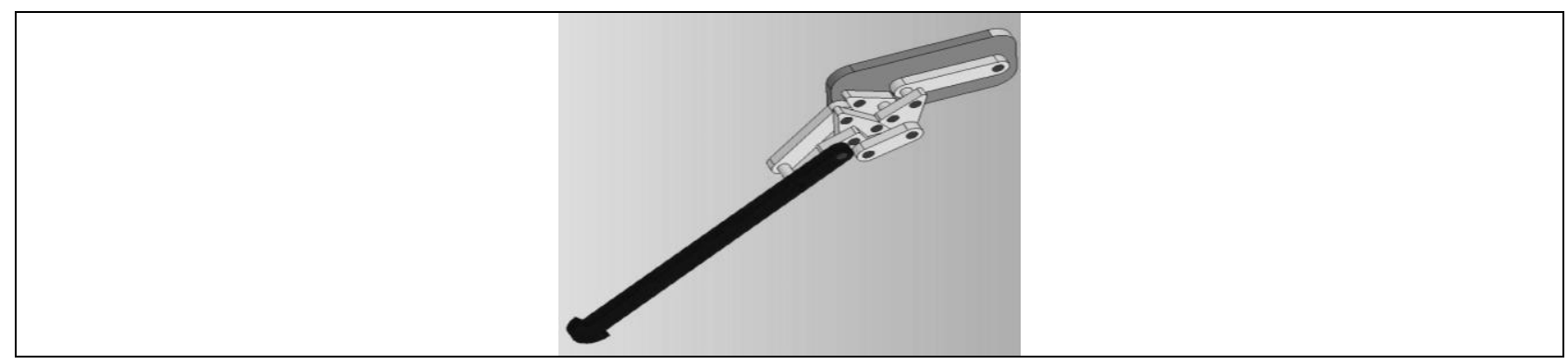

Fig. 10. Optimal inverse model solution with the 1 link as a frame and the 6 link for the effector

By using the linkage from Fig. 6 with the 1 link for frame and the 5 link for effector the solution (Fig. 9) is an optimal one having for the inverse model a single passive modular group deduced from the BT 30 Baranov truss (Crossley, 1968; Manolescu et al., 1972; Pelecudi, 1967, Voinea \& Stroe, 2000; Angeles, 2003, Kakudou et al., 2013).

The linkage (Fig. 7) may be used for an optimal inverse model solution with the 1 link as a frame and the 6 link for the effector. The mechanism presented in Fig. 10 has for the inverse structural model a single passive modular group based on the BT 9 truss.

\section{Conclusion}

The paper puts into evidence new optimal solutions for bi-mobile mechanisms with a high performance of their inverse models. Such mechanisms with a single passive group with 8 elements for the inverse model presented in Fig. 9 and Fig. 10 are firstly mentioned in the literature. The passive groups with 8 links deduced from 
Baranov trusses are also new ones and are respectively given in Fig. 11, Fig. 12 and Fig. 13, Fig. 14.

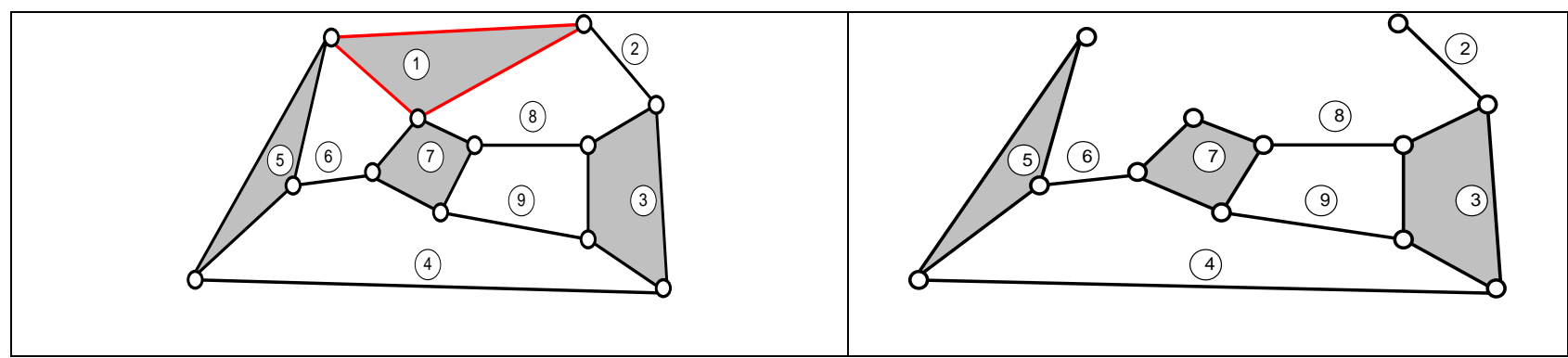

Fig. 11. The inverse model of mechanism given in Fig. 9

Fig. 12. The 8 link passive modular group

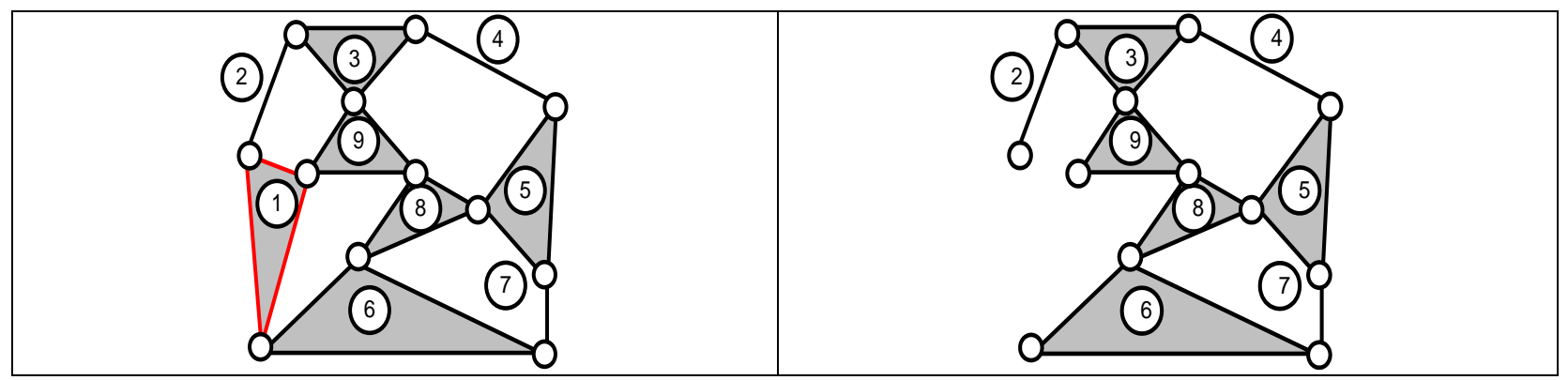

Fig. 13. The inverse model of mechanism given in Fig. 10

Fig. 14. The 8 link passive modular group

It is demonstrated their applicability for mechanical structures when a high precision is desired. These new configurations may be used for robot arms or for pedipulators systems for sustaining and displacement of mobile platforms.

\section{References}

Angeles, J. (2003). Fundamentals of Robotic Mechanical Systems: Theory, Methods and Algorithms, Springer-Verlag New York

Comănescu, Adr.; Comănescu, D.; Dugaesescu, I. (2010). Bazele modelarii mecanismelor, Editura Politehnica Press, Bucureşti, (Basics of modeling mechanisms, Politehnica Publishing Press, Bucharest)

Crossley, F.R.E. (1968). Structural Synthesis of a Four Bit Binary Adding Mechanisms, 10-th ASME Mechanisms Conference, Paper no.68 MECH 25 Atlanta Kakudou, T., Watanabe, K., Nagai, I. (2013). Study on Mobile Mechanism of a Climbing Robot for Stair Cleaning: a Translational Locomotion Mechanism and Turning Motion, Journal Artificial Life and Robotics, Springer-Verlag New York Manolescu, N.; Kovacs, Fr., Orănescu, A. (1972). Teoria mecanismelor şi a maşinilor, Editura Didactică şi Pedagogică, Bucureşti, (Theory of mechanisms and machines, Didactic and Pedagogic Publishing House, Bucharest)

Pelecudi, Chr. (1967). Bazele analizei mecanismelor, Editura Academiei Române, Bucureşti, (Basis of analysis mechanisms, Romanian Academy Publishing House, Bucharest)

Voinea, R.; Stroe, I. (2000). Mechanical Structures Dynamics, Editura Academiei Române, Bucureşti (Romanian Academy Publishing House, Bucharest) 